\title{
Assistance protocol for patients submitted to image examinations based on diagnosis from nanda and intervetions from NIC
}

\begin{abstract}
Objective: To develop a nursing care protocol as a basis for NANDA nursing diagnoses and NIC interventions for patients submitted to image of computed tomography and magnetic resonance.

Method: It is a study of bibliographic review of articles published between 2007 and 2017, with the intention of finding a nursing care protocol. As no related scientific publications were found, a two-step protocol was developed. First step: selection of the diagnoses according to their domains and NANDA definitions, grouping them and confronting them with the scientific literature, generating the nursing diagnoses considered the main ones for the care of the patients in these examinations. Second stage: Elaborated interventions based on the NIC for each nursing diagnoses.
\end{abstract}

Result: 30 nursing diagnoses were established. After a critical analysis, the protocol was defined with 11 diagnoses and their respective interventions.

Conclusion: Complications of procedures may occur before, during and after the tests, due to various modifiable and non-modifiable factors and/or conditions. The protocol is efficient for patients referred internally or externally from the hospital scope, regardless of previously know their clinical data.

Keywords: image diagnostic, nursing care, means of contrast, adverse reactions, computed tomography, magnetic resonance
Volume 5 Issue $6-2018$

\author{
Bruno Vilas Boas Dias,' Rafaela Cristiane \\ Santos Santana, ${ }^{2}$ Rafael Antônio da Silva ${ }^{3}$ \\ 'Professor master of the Undergraduate Course in Nursing, \\ Padre Anchieta University Center, Brazil \\ ${ }^{2}$ Graduating in Nursing, Padre Anchieta University Center, Brazil \\ ${ }^{3}$ Specialist Course in Nursing, Padre Anchieta University Center, \\ Brazil
}

Correspondence: Bruno Vilas Boas Dias, Professor master of the Undergraduate Course in Nursing, Padre Anchieta University Center and Campo Limpo Paulista Center, Brazil, Email bruno.deas@faccamp.br

Received: October 16, 2018 | Published: November 22, 2018

\section{Introduction}

The Nursing area of practice covers several fields, for example, radiology is one of the fields of work for the nurse that requires beyond the usual skills; quire, Know-how and skills in the aerial of critical care and of emergencies for the attendance. Currently there are specializations recognized by the Federal Nursing Council (FNC), which also requires, through FNC resolution number 543/2017, "the presence of nurses in these units" as well as a Resolution "for the duties of nurses in radiology" according to FNC resolution number 211/1998.

The Diagnostic Imaging Center, also known as Imaging Unit, is comprised of the following diagnostic support services: conventional radiology; computed tomography; ultrasonography; hemodynamics and magnetic resonance imaging. ${ }^{2}$ The sector is considered an essential area in the operation of the in-hospital because it has a state-of-theart scientific technical development that allows the effectiveness in the clinical or surgical diagnosis process of the diseases with direct consequences in the selection of the type of treatment for the patients.

Exams such as computed tomography, for example, use x-ray ionizing radiation to produce cross-sectional images of the object of study where the patient is exposed to higher radiation doses. Some specific therapeutic groups deserve special consideration as to the risk of exposure to radiation, such as: pregnant women, and children, due to young embryo, fetal, and child cells being accelerated. ${ }^{3}$ Exposure of a computed tomography scan in some tests is equivalent to nearly four years of exposure to background radiation, but the potential benefit of the examination, when well indicated, justifies the diagnostic procedure. ${ }^{3}$ Magnetic resonance imaging is a diagnostic imaging method that uses a uniform and powerful magnetic field to generate images in the three anatomical planes: the sagittal, coronal and axial without repositioning the patient. The basic mechanism involves the interaction of the magnetic field with the molecules of hydrogen (abundant in the human body) and radiofrequency pulses, which turns it into an image. ${ }^{4}$ Currently, magnetic resonance imaging has assumed a gradual importance in the diagnosis of imaging due to its high potential for differentiation and characterization of the anatomy and pathologies, without the use of ionizing radiation. In order to perform imaging examinations, patient safety is the responsibility of the nurse and the multidisciplinary team of the sector, which consists of identifying and preventing intrinsic and extrinsic risk factors through: questioning and clinical follow-up, protocol institution. As a characteristic, the imaging center receives patients both intra- and extra-hospital. ${ }^{5,6}$

The justification for the present study is based on the lack of research that brings together essential elements to offer a safe care to patients submitted to computed tomography and MRI, and there is a need to seek evidence in the national and international literature on the subject, in order to qualify the nursing assistance in order to guarantee the patient to perform these tests more safely. Thus, the implantation of a nursing protocol will enable and facilitate clinical adjustments of the multidisciplinary team and critical evaluation of care, whose objective is to prevent complications and hospital diseases. It will also allow the analysis of risk factors and the possible complications of computed tomography and magnetic resonance imaging examinations. The purpose of this analysis is to know the risk factors related to care, and to establish more effective preventive methods, with actions and interventions of nursing according to the universal 
language about nursing care to the clients that perform these imaging tests. To this end, the nurse must follow the normative precepts of the North American Nursing Diagnosis Assosiation (NANDA), clinical judgment of the potential and actual problems of the patients and based on the interventions of the Nursing Classification and Clinical Effectiveness (NIC). ${ }^{7,8}$

\section{Objective}

Propose a nursing care protocol, based on the nursing diagnoses of the NANDA (2018-2020) and interventions the NIC for patients submitted to computed tomography and magnetic resonance imaging.

\section{Methods}

The purpose of this study was to use the literature review method, from 2007 to 2017, in order to find nursing protocols for patients who underwent computed tomography and magnetic resonance imaging. The following data were used as data sources: Nursing Databases, Medical Literature Analysis and Retrieval Sistem Online, Literatura Latino-Americana e do Caribe em Ciências da Saúde, and virtual library Scientific Elletronic Library Online. The Boolean operator "and" was used for the association of the following descriptors: Imaging Diagnosis, Nursing Care, Contrast Media, Adverse
Reactions, Computed Tomography and Magnetic Resonance Imaging. However, no published protocols for the patient were found on computed tomography and magnetic resonance scans. Thus, to reach the objective, two steps were established. The first step consisted in the selection of some diagnoses according to their domains and NANDA definitions, grouping them and confronting them with the scientific literature, thus generating the nursing diagnoses considered the main ones for the care of patients in the examinations of computed tomography and magnetic resonance imaging. In the second stage, interventions were elaborated based on the Classification of Nursing Interventions, for each one of the diagnoses.

\section{Results}

Initially, 30 nursing diagnoses were established based on intrinsic and extrinsic factors that may contribute to the development of complications in patients performing imaging studies. After a critical analysis, 11 nursing diagnoses were selected, prioritizing the main data and the main problems encountered in these visits. The protocol was defined with 11 nursing diagnoses and their respective interventions selected. Next, the protocol elaborated presenting the selected nursing diagnoses, the interventions through Table 1 and after their respective discussions.

Table I Main nursing diagnoses by NANDA and their respective interventions by NIC

\begin{tabular}{ll}
\hline Nursing diagnosis & Nursing interventions \\
\hline $\begin{array}{l}\text { Risk of adverse contrast media } \\
\text { with iodine }\end{array}$ & $\begin{array}{l}\text { To identify the risk factors for adverse reactions to the contrast medium, such as: age and chronic diseases; } \\
\text { monitor vital signs before and after administration of the contrast medium; monitor the appearance of the first } \\
\text { signs of allergic reaction as: dyspnoea, urticaria, welts, cutaneous angioedema, nausea, vomiting and restlessness; } \\
\text { guide the patient and their families about the risks and the prevention of future episodes. }\end{array}$ \\
Risk of allergic response & $\begin{array}{l}\text { Monitor blood glucose levels if indicated; monitor the onset of signs and symptoms of hypoglycemia, such as: } \\
\text { sweating, tachycardia, dizziness, drowsiness, fatigue, numbness in the lips or limbs. }\end{array}$ \\
Risk of unstable glycemia & $\begin{array}{l}\text { Evaluate the venous network of the patient before peripheral venous puncture, verify intravenous catheter size, } \\
\text { position and permeability; administering the intravenous contrast medium at the appropriate rate, and when } \\
\text { performed in an infusion pump, to monitor all administration; to test infusion viability in hospitalized patients with } \\
\text { peripheral catheters, previously punctured outside the imaging sector; monitor the signs of infiltration, phlebitis } \\
\text { and extravasation at the puncture site. }\end{array}$
\end{tabular}

Risk of ineffective renal perfusion

Risk of electrolyte imbalance

Anxiety

Risk of infection

Risk of fall

Monitor serum urea and creatinine electrolyte levels when one or more risk factors are identified.To administer liquids according to medical prescription, based on adequate protocol.

Use calm and reassuring approach; clarify expectations according to the patient's behavior; explain all procedures, including sensation that the patient may have during the procedure; stay with the patient to promote safety and reduce fear; listen carefully to the patient; create atmosphere that facilitates trust between the patient and the nursing team.

Wash hands before and after each patient care activity; establish universal precautions according to the indications and pathologies of the clients; wear gloves, as required by universal precaution protocols; ensure aseptic handling of all intravenous lines; perform the exchange of the disposable syringe, the contrast injector to each patient change, according to the manufacturer's information and protocol of the institution.

Identify cognitive or physical deficits of the patient, capable of increasing the potential for falls; identify behaviors and factors that affect the risk of falls; locking the wheels of the wheelchair, bed or stretcher during patient transfer; accompany patient upon getting up from the examination tables, after finishing; guide patient to call the team for help and not get up abruptly.

\section{Discussion}

\section{Risk of adverse contrast response with iodine/Allergic response risk: It may occur due to the pharmacological characteristics of the intravenous contrast medium, and the immune response of the patients exposed to the use of the contrast medium}

Approximately $90 \%$ of imaging complications following intravenous radiopharmaceuticals, adverse reactions to contrast media may occur after single or multiple administrations. It is quite usual to classify them as to its etiological mechanism: anaphylactoid or chemotoxic, its degree of severity as mild, moderate and severe, and the time elapsed after its administration. Approximately $70 \%$ of adverse reactions occur within the first 30 minutes and up to 7 days after administration of the radiopharmaceutical, considered respectively as immediate and late reactions. ${ }^{9}$ The main clinical manifestations of allergic anaphylactoid responses are: urticarias, coryza, hypotension 
with tachycardia, nausea, vomiting, bronchospasm, laryngeal edema and more severe manifestations such as shock and severe respiratory failure. And of chemotoxic agents that are: sensation of heat, nausea and vomiting, cardiac arrhythmias, hypertension, renal failure, seizures among others. ${ }^{10}$

Unstable glycemia risk: May occur due to the recommended fasting time for each test due to the need for administration of contrast medium. According to the Brazilian Diabetes Society, Hypoglycemia is the decrease in glycemic levels to below $70 \mathrm{mg} / \mathrm{dL} .{ }^{11}$ Usually this drop leads to neuroglycogenic symptoms (hunger, dizziness, weakness, headache, confusion, coma, seizure), and sympathetic system release symptoms (sweating, tachycardia, seizure, tremor). Hypoglycaemia is not a problem exclusively associated with diabetes, it can occur in healthy patients who have a prolonged fast, but it is less recurrent. ${ }^{12,13}$

Impaired tissue integrity risk: May occur due to peripheral intravenous extravasation of the contrast medium during its administration. Contrast extravasation is considered an adverse event to the site of intravenous administration of the contrast medium. Most of the extravasation evolves without complications, however, volumes as large as $50 \mathrm{ml}$ or more can cause tissue damage adjacent to the puncture site. According to international studies, extravasation occurs between 0.3 and $3.6 \%$ of the administrations in the intravenous contrast medium. ${ }^{10}$

Risk of ineffective renal perfusion/Risk of electrolyte imbalance: May occur due to alteration in renal filtration of patients possibly undergoing administration of contrast medium. This complication is due to impaired renal function, defined by the reduction in the glomerular filtration rate that occurs after the intravenous use of the contrast medium. There is the likelihood of the patient having contrast-induced nephropathy, one of the most serious consequences of using contrast, with the third most frequent cause of renal failure in hospitalized patients, with an average incidence of $10.2 \%$. The main risk factors for the development of NIC are: diabetes mellitus, congestive heart failure, patients over 70years old, hypovolemia, concomitant use of nephrotoxic agents and dehydrated patients. ${ }^{14,15}$

Anxiety: Can occur due to lack of knowledge of the procedure and/or emotional state, discomfort when performing the exam and/ or knowing the clinical diagnosis presented. Anxiety is a disorder experienced in the hospital and laboratory environment that usually arises in response to threats such as lack of knowledge of clients, likely to trigger disruptions, limiting the patient many times to face their illnesses, making clinical diagnosis difficult. It causes the patient to go through situations of insecurity, to experience moments apprehensive, and uncomfortable. Often unexplained physical symptoms such as restlessness and tachycardia increase. ${ }^{16}$

Risk of infection: It may occur due to the handling and aseptic techniques performed in the invasive procedures, such as: peripheral venous puncture in and injection of the intravenous contrast medium. Intravascular catheters provide therapeutic benefits and are used for specialized diagnoses and treatments, although such catheters provide the necessary vascular access, their use puts patients at risk of significant complications during their use. As the primary bloodstream infection, related to the insertion of the vascular catheter, can be associated with its location, solution infused, care provided by the professional who performed the puncture procedure and infusion of solution and devices used. ${ }^{17,18}$ In Brazil, the mortality attributed to bloodstream infections ranges from $6.7 \%$ to $75 \% .^{19}$
Risk of falls: May occur due to the patient's physiological and psychomotor condition at the time of the test. Falls are one of the most prevalent adverse events in the hospital and laboratory environment, about $5 \%$ of which result in fractures and $5 \%$ to $11 \%$ of severe damage. ${ }^{20}$ In most cases, intrinsic physiological and musculoskeletal factors predispose the falls such as: reduced motor power and muscular power; changes in walking pattern; visual and auditory deficit; limitation of range of motion and change of balance. The declines that occur on the neuromuscular system compromise the postural control system, which responds by controlling the balance. ${ }^{21}$ The consequences of the event can lead to damages, increase length of hospital stay, increase clinical complications and even hospital treatment costs. ${ }^{20}$

Risk of contamination: May occur due to high exposure or repeated exposure of the patient to radiation. Even with safety regulatory standards for the implementation of health care, high exposure to ionizing radiation, can cause damage to the structure of cells, when applied in a focused way in small areas of the body and for a long time. ${ }^{3,22}$ The doses of radiation used in the diagnostic tests do not have the potential to cause cell death, according to established regulations, but may eventually cause a genetic mutation with the potential to cause cancer or congenital diseases in the affiliation, the effects are dependent on the doses received during the life. A group of more attention are children and pregnant women, because the young embryo, fetus, and child cells, because they are developing fast. ${ }^{3,22}$

Interrupted breastfeeding: May occur due to interruption of breastfeeding related to maternal use in the contrast medium, and may be absorbed by the baby via breast milk, with a high probability of renal toxicity to the infant. In the intravenous administration of radiopharmaceuticals in breastfed women, a concentration of the medication occurs in the milk, and can be absorbed by the infant, reaching levels toxic to the baby. Suspension or maintenance of breastfeeding is performed according to the dosage of the drug administered. ${ }^{23}$

\section{Conclusion}

The set of interventions presented in the 11 selected nursing diagnoses highlight the problems that clients experience when performing imaging tests and the need for each specific intervention for each patient profile.

The results obtained in this study showed that, nursing interventions help to prioritize decision making and provide greater safety of patients submitted to computed tomography and magnetic resonance imaging. By explaining that, regardless of the patients' clinical data, whether they are referred internally or externally from the hospital scope, complications may occur before, during and after the tests due to various factors and/or modifiable conditions such as feeding, anxiety and not such as age and chronic diseases. The protocol is efficient both for internal and external patients, regardless of prior knowledge of this information.

\section{Acknowledgments}

None.

\section{Conflicts of interest}

Authors declare that there is no conflict of interest. 


\section{References}

1. Conselho Federal de Enfermagem. Legislações.

2. Colégio Brasileira de Radiologia e Diagnóstico por Imagem. Publicações. 2017.

3. David WI, Shigueoka C. Exposição à radiação durante exames de imagem: dúvidas frequentes. Diagn Tratamento. 2010;15(3):143-145.

4. Westbrook C. Manual de técnicas de ressonância magnética. 3rd ed. Rio de Janeiro: Guanabara Koogan; 2010.

5. Marinho RC. Manual de práticas e assistências de enfermagem no setor de diagnóstico por imagem. São Paulo: Iátria; 2010.

6. Bianco RPR. Enfermagem no centro de diagnóstico por imagem. In: Nobrega AI, editor. Tecnologia radiológica e diagnóstico por imagem. 4th ed. São Paulo: Difusão Editora; 2010. p. 241-268.

7. North American Nursing Diagnosis Assosiation. Diagnósticos de enfermagem da NANDA: definições e classificações: 2015-2017.

8. Bulechek GM, Butcher HK, Dochterman JM. Classificação das intervenções de enfermagem NIC. 5th ed. Elsevier; 2010.

9. Juchem BC, Dall'Agnol CM, Magalhães AMM. Contraste iodado em tomografia computadorizada: prevenção de reações adversas. Rev Bras Enfermagem. 2004;57(1):57-61.

10. Juchem BC, Dall'Agnol CM, Magalhães, AMM. Reações adversas imediatas ao contraste iodado intravenoso em tomografia computadorizada. Rev Latino-am Enfermagem. 2007;15(1):1-7.

11. Sociedade Brasileira de Diabetes. 2017.

12. Brasil. Ministério da Saúde. Secretaria de Atenção à Saúde. Departamento de Atenção Básica. Diabetes mellitus. Brasília: Ministério da Saúde. 2006.

13. Teixeira AM, Tsukamoto R, Lopes CT, et al. Risco de glicemia instável: revisão integrativa dos fatores de risco de diagnósticos de enfermagem. Rev Latino-am Enfermagem. 2017;25:e2893.
14. Passamani DL, Fuchs BL, Franco CG. Nefropatia induzida por contraste (NIC) em pacientes adultos internados submetidos à tomografia computadorizada por contraste. J Bras Nefrol. 2014;36(4):446-450.

15. Maccariello E. Nefropatia induzida por contraste. J Bras Nefrol. 2016;38(4):388-389.

16. Gullich I, Ramos AB, Zan TRA, et al. Prevalência de ansiedade em pacientes internados num hospital universitário do Sul do Brasil e fatores associados. Rev Bras Epidemiol. 2013;16(3):644-657.

17. Modes PSSA, Gaíva MAM, Rosa MKO, et al. Cuidados de enfermagem nas complicações da punção venosa periférica em recém-nascidos. Rev Rene Fortaleza. 2011;12(2):324-332.

18. Mesiano ERAB, Hamann EM. Infecções da corrente sanguínea em pacientes em uso de cateter venoso central em unidades de terapia intensiva. Revista Latino-Americana de Enfermagem. 2007;15(3):1-8.

19. Xavier PB, Oliveira RC, Araújo RS. Punção venosa periférica: complicações locais em pacientes assistidos em um hospital universitário. Rev Enferm. 2011;5(1):61-66.

20. Costa-Dias MJM, Ferreira PL. Escalas de avaliação de risco de quedas. Rev Enf Ref. 2014;4(2):153-161.

21. Bruniera CAV, Rodacki ALF. Respostas estabilométrica de jovens e idosos para recuperar o equilíbrio após uma perturbação inesperada controlada. Rev educ fis. 2014;25(3):345-351.

22. D’Ippolito G, Medeiros RB. Exames radiológicos na gestação. Radiol Bras. 2005;38(6):447-450.

23. Brasil. Ministério da Saúde. Secretaria da Atenção à Saúde. Departamento de Ações Programáticas e Estratégicas. Amamentação e uso de medicamentos e outras substâncias. 2nd ed. 2010. p. 1--92. 